\title{
EFFECT OF ORAL CLONIDINE PREMEDICATION ON THE ONSET AND DURATION OF SPINAL ANESTHESIA WITH HYPERBARIC BUPIVACAINE
}

Shruthi Jayaram ${ }^{1}$, Srinivas Kulkarni², Radhesh Hegde ${ }^{3}$

\section{HOW TO CITE THIS ARTICLE:}

Shruthi Jayaram, Srinivas Kulkarni, Radhesh Hegde. "Effect of Oral Clonidine Premedication on the onset and duration of Spinal Anesthesia with Hyperbaric Bupivacaine". Journal of Evolution of Medical and Dental Sciences 2014; Vol. 3, Issue 46, September 22; Page: 11262-11270,

DOI: $10.14260 /$ jemds/2014/3468

ABSTRACT: BACKGROUND: Spinal anesthesia is the most common technique used for lower abdominal surgeries. Hyperbaric Bupivacaine has limited duration of action. Clonidine has been used to prolong the duration of local anaesthetic. Hence in our study, we studied the effects of oral clonidine premedication on spinal anaesthesia with hyperbaric Bupivacaine with reference to sedation, onset and duration of sensory and motor blockade including its effects on hemodynamic status. METHODS: Prospective randomized, double - blinded placebo, control study, two groups of thirty patients each were selected. One group (Group C) received $150 \mu$ g clonidine tablets and the other group (Group B) received placebo, 90 minutes before anesthesia. Primary outcome were sedation, onset and duration of sensory and motor blockade. Hemodynamic and other effects of the study drug were the secondary outcomes. RESULT: It was observed that clonidine premedication resulted in higher incidence of moderate sedation, hastens the onset of sensory block but has no effect on the onset of motor blockade. It prolonged the duration of sensory and motor blockade. Clonidine at a dose of $150 \mu \mathrm{g}$ is not associated with any greater change in heart rate and blood pressure following spinal anesthesia. CONCLUSION: We conclude that oral clonidine premedication,in patients with hyperbaric bupivacaine hastesns the onset of sensory block and prolongs the duration of sensory and motor anesthesia with moderate sedation.

KEYWORDS: Spinal Anesthesia, Bupivacaine, clonidine.

INTRODUCTION: Regional anesthesia has been known to be the best technique for lower limb and lower abdominal surgeries especially in patients with impaired ventilatory performances. It causes minimal intervention of airways, reduces the stress response during surgery and at the same time provides post-operative pain relief. Spinal anesthesia is the most common form of regional anaesthetic procedure being practiced today due to its safety, reliability, rapid onset of neural blockade and the ease with which it is performed.

But expertise and time are required for epidural anesthesia. It would be very useful to prolong the duration of spinal analgesia by alternative techniques or methods for lengthened surgeries. Several agents have been used to prolong the duration of spinal anesthesia. Vasoconstrictors like phenylephrine, opioid, dextran-40; carbonated local anesthetics, proteins, potassium etc. are some of well-known agents. ${ }^{1}$

Clonidine, $\alpha_{2}$ adrenergic agonist has been used by anesthesiologists as a pre medicant since many years. Advantages known to include are, decrease in minimum alveolar anaesthetic concentration (MAC) of inhaled anaesthetics ${ }^{2}$, decrease in the dose of narcotics required to prevent reflex cardiovascular response to tracheal intubation or surgery 3 and potent analgesic properties. ${ }^{4}$ Regional anesthesia too was benefited by using clonidine, either by spinal or epidural administration. 
Clonidine has also been used as an adjuvant postoperative pain alternative to opioid. In view of wealth of literature supporting the potent analgesic properties of clonidine in central neuraxial blockade, we aimed to study the effect of oral clonidine premedication during spinal anesthesia with respect to the duration of sensory and motor blockade.

METHODOLOGY: The study protocol was approved by the hospital ethics committee. Sixty adult patients belonging to ASA grade I and II aged between 20 to 60 years scheduled for elective lower abdominal and lower limb surgeries under spinal anesthesia were selected. Patients with a history of cardiovascular disorders, diabetes, disorders known to affect autonomic function, and those on medications known to affect cardiovascular functions were excluded from the study.

Our study was a double blind randomized placebo controlled study. 60 packets of one tablet in each were made by an independent observer. Among these, 30 tablets were clonidine $150 \mu \mathrm{g}$ (Group C) and the remaining was placebo (Group B). All the packets were mixed and any packet was picked up according to lots by the investigator on the morning of surgery and given to the patients 90 minutes before anesthesia to be taken orally with sips of water. Baseline heart rate, systolic and diastolic blood pressure were measured before premedication.

After arrival to the operation theatre, baseline heart rate, systolic, diastolic blood pressures were measured using an automated noninvasive monitor. Scoring was done for sedation using a 5 point Ramsay scale. Score 1: Anxious, agitated, and restless. Score 2: Awake, cooperative, oriented, tranquil. Score 3: Semi asleep responds only to verbal commands. Score 4: Asleep with brisk response to glabellar tap or loud auditory stimulus. Score 5: Asleep with sluggish response to glabellar tap or loud auditory stimulus. Score 6: Non responsive.

After the above assessments were made, an 18 gauge intravenous cannula was inserted under local anaesthesia and lactated ringers solution of $15 \mathrm{ml} / \mathrm{kg}$ was infused for preloading. The patients were placed in the lateral decubitus position for lumbar puncture. Under strict aseptic precautions a lumbar puncture was performed through a midline approach using either a 22 or 23 gauge spinal needle at the $\mathrm{L}_{2} \mathrm{~L}_{3}$ inter vertebral space. Once a free flow of cerebrospinal fluid was obtained, $2.5 \mathrm{ml}$ of $0.5 \%$ Bupivacaine was injected at a rate of $0.2 \mathrm{ml} / \mathrm{s}$.

After the spinal injection the patient was returned to supine position and was retained in that position for at least 20 minutes before positioned for surgery. Dermatome levels of sensory anaesthesia were evaluated by pin prick. The levels of pin prick analgesia were studied every minute for the first twenty minutes and then at 10 minutes intervals until analgesia to pin prick recovered to the $\mathrm{L}_{1}$ segment.

The highest sensory levels and the time from injection to attainment of highest level of sensory block were evaluated. Time for two segment, four segment regression and regression of sensory blockade to $\mathrm{L}_{1}$ segment was noted. Time for onset of complete motor block was assessed and graded using modified Bromage scale. Scale 0 - Free movements of legs and feet, with ability to raise the extended leg. Scales 1 - Inability to raise extended leg and knee flexion is decreased, but flexion of feet and ankles is present. Scale 2 - Inability to raise leg or flex knees, flexion of ankle and feet Present. Scale 3 - Inability to raise leg, flex knee or ankle, or move toes.

Time for recovery of motor blockade at $\mathrm{L}_{2}$ level (hip flexion) was assessed. Intra operatively, the blood pressure and heart rate were monitored at 1 minute intervals for the first 10 minutes and later every 10 minutes for 1 hour. Hypotension $<90 \mathrm{mmHg}$ of systolic blood pressure was treated 
with inj. mephenteramine $6 \mathrm{mg}$ increments intravenous doses. Bradycardia $<50$ beats per minute was treated with inj. atropine $0.6 \mathrm{mg}$ intravenously.

We excluded the patients from the study in whom $\mathrm{T}_{6}$ blockade was not achieved, patients on whom lumbar puncture could not be performed at $\mathrm{L}_{2-3}$ space and in whom supplementation of regional block was required. Data obtained are presented as mean \pm standard deviation. Age and weight of the patient was compared using Student's t-test and sex distribution was compared using Chi-square test.

Sedation was compared using Z-Gaussian test. Intergroup comparison of onset and duration of sensory as well as motor blockade was done using Student's t-test. Hemodynamic parameters comparison between groups was done again by Student's t-test. Intergroup comparison of requirements of atropine and vasopressors was made by Fisher's exact test.

A ' $p$ ' value of $>0.05$ was taken to be statistically not significant, a 'p' value of $<0.05$ as statistically significant and a ' $p$ ' value of $<0.01$ as statistically highly significant and a ' $p$ ' value of $<0.001$ as statistically very highly significant.

RESULTS: The patient's demographic profile was comparable in both the groups (Table.1). Both the groups had male predominance (Table.2) There was no significant differences in sedation scores at the time of premedication ( $0^{\text {th }}$ minute), $(\mathrm{p}=0.313)$, (Table III). At $90^{\text {th }}$ minute 25 patients in clonidine group were sedated with a maximum percentage of patients belonging to count 3 sedation score of Ramsay scale (83.22\%).

None of the patients had sedation score of 5 or 6 . In the placebo group sedated patients were just 3 in number (10\%) and thus when both groups were compared, the differences in sedation scores were statistically very highly significant. ( $p<0.0001)$, (Table III). The time for onset of sensory block was compared between two groups using Student's t-test.

Intergroup comparison showed a statistically significant difference between the two groups ( $p=0.045)$, (Table I\&IV), the time for regression of sensory blockade to 2 segment, 4 segment and to $\mathrm{L}_{1}$ were studied. Intergroup comparison of two segment regression, four segment regression and regression to $L_{1}$ between Group $C$ and group B was done and the differences were statistically very highly significant ( $p=0.000)$, (Table IV).Time of onset of complete motor block was also studied.

Intergroup comparison showed no statistically significant difference in the onset between the two groups ( $\mathrm{p}=0.915)$, (Table IV). The intergroup comparison showed statistically very highly significant difference in the recovery of motor block between the placebo and the clonidine groups ( $p$ $=0.000$ ), (Table IV). The baseline heart rates were comparable in study and control group. The pre spinal heart rate was also statistically comparable in both the group the intergroup comparison of change in pre spinal to lowest heart rate value was not statistically significant (graph I)

Baseline systolic and diastolic blood pressure recorded preoperatively was comparable in each group. Preoperative (baseline) mean systolic blood pressure in clonidine group when compared with control group showed no significant differences $(\mathrm{p}=0.199)$ (Table V). Similarly mean diastolic blood pressure in two groups were comparable to each other $(\mathrm{p}=0.172)$ (Table VI).

Pre spinal values of systolic and diastolic blood pressure recorded during our study also were compared. Intergroup comparison of mean systolic and intergroup comparison of mean diastolic blood pressures was statistically not significant. $\mathrm{p}$ values $(\mathrm{p}=0.121, \mathrm{p}=0.355$ respectively) (Table V 


\section{ORIGINAL ARTICLE}

Table VI). Following spinal anaesthesia, the lowest mean blood pressures observed in clonidine and study groups were also recorded.

Intergroup comparison of lowest mean systolic blood pressure and intergroup comparison of lowest mean diastolic blood pressures were statistically not found to be significant $(\mathrm{p}=0.08, \mathrm{p}=$ 0.500 respectively) (Table V,VI). 2 patients in Group C and 2 patients in group B received vasopressors.

There was no change in mean systolic as well diastolic pressure from premedication (Baseline) to pre spinal values (Table V, Table VI). But a definite fall in blood pressures following spinal anaesthesia was noticed and Group C, showed a mean systolic blood pressure change of 19.23 $\pm 10.36 \mathrm{~mm}$ of $\mathrm{Hg}$ and a mean diastolic pressure change of $15.17 \pm 9.21 \mathrm{~mm}$ of $\mathrm{Hg}$.

Group B had a change in mean systolic pressure of $24.63 \pm 11.67 \mathrm{~mm}$ of $\mathrm{Hg}$ and change in mean diastolic pressure of $19.47 \pm 10.77 \mathrm{~mm}$ of $\mathrm{Hg}$. When the groups were statistically compared, the changes in systolic and diastolic pressure were similar in both the groups. $(p=0.063, p=0.102$ respectively) (Table V, Table VI).

DISCUSSION: Spinal Anaesthesia is one of the most widely practiced regional anaesthesia technique for lower abdominal surgeries and various drugs are being used alone or in combination to increase the duration of spinal anaesthesia. Clonidine has been successfully used in the past and recent years as a premed cant due its sedation and anxiolytic properties. Sedative action may be due to decreased tonic activity of the locus coeruleus which modulates the stimuli arriving at the central nervous system $^{6}$.In our study clonidine at $150 \mu \mathrm{g}$ had good sedative effect.

Studies done using different dose of clonidine have shown that when used at $0.2 \mathrm{mg}$, clonidine produced a significant reduction in anxiety and at $0.3 \mathrm{mg}$ produced significant decrease in arterial pressure along with sedation. ${ }^{7} \mathrm{We}$ found in our study that the time taken for the attainment of highest level of sensory block was little earlier in the clonidine group compared to placebo.

The time for 2 segment regression, 4 segment regression and regression to $L_{1}$ of sensory block in clonidine group was much prolonged than the placebo group. Our study was not in accordance with study done by Bennett $\mathrm{F}$ et $\mathrm{ai}^{8}$, who showed that subarachnoid clonidine but not oral clonidine prolonged the duration of sensory block. In our study we found no difference in the time of onset of complete motor block between the two groups and the duration of motor block was prolonged in clonidine group.

Thus, we confirm the prolongation of sensory and motor blockade by oral clonidine during spinal Bupivacaine anaesthesia. Studies have shown that intra thecally administered clonidine also prolongs the duration of sensory and motor block. ${ }^{8}$ The oral dose of clonidine we used was $150 \mu \mathrm{g}$ in all patients and this dose seems to be too small to elevate the concentration of clonidine in cerebrospinal fluid.

Clonidine is highly lipid soluble and crosses the tissue barriers rapidly and therefore may interact with $\alpha$-adrenergic receptors at spinal and supra spinal sites within the central nervous system. ${ }^{9}$

In our study, the changes in systolic as well as diastolic blood pressures with or without premedication were minimal. Since clonidine is an antihypertensive, we anticipated low prespinal blood pressures than control group. 
In contrast, the pre spinal and lowest blood pressure was similar in both groups. Our study coincided with the study done by Ota et al.10 The incidence of hypotension in the two groups was almost same and the number of vasopressors agent we used too were similar in both the groups. Thus, it was very clear from our study that no significant fall in blood pressure occurs with a single oral dose of clonidine premedication of $150 \mu \mathrm{g}$.

In our study, clonidine treated groups did not differ significantly with respect to heart rate compared to control group either in baseline or in pre spinal values indicating our premedication did not have any effect on heart rate. Following spinal anaesthesia, we noted a fall in heart rates in both the groups due to sympatholysis. Clonidine did not cause any exaggerated fall. Several authors demonstrated the low pre spinal blood pressure following clonidine premedication and incidence of hypotension following spinal anaesthesia. ${ }^{11}$

Few studies showed incidences of bradycardia at a dose of $(5 \mu \mathrm{g} / \mathrm{kg})^{12}$ and studies have shown bradycardia at 200/ $\mu$ g. ${ }^{13}$ We did not see any exaggerated changes in heart rate or blood pressure following premedication like severe hypotension or severe bradycardia. It is said that despite the presence of the $\alpha_{2}$ agonist agent, patients will be able to generate a sympathetic response to surgery and hypotension. ${ }^{14,15}$

This suggests that anesthetically effective doses of clonidine do not prevent increase in serum catecholamine in response to modulation of efferent sympathetic nerve traffic. ${ }^{15}$ the baro reflex sensitivity is also reported to be enhanced in humans ${ }^{15}$ and in animals following clonidine premedication. Limitations of our study need to be discussed, which might not have significant influences in our study.

Though the study was conducted in a double blind fashion, observer bias cannot be excluded completely. We used clonidine as pre medicant in a dose of $150 \mu \mathrm{g}$ orally and changes in weight, volume of distribution, gastric emptying, metabolism etc. may cause different plasma levels of clonidine in patients. The type of surgery might have influence on recorded lowest blood pressures and heart rate values.

CONCLUSION: We conclude that clonidine as oral premedication produces higher incidence of moderate sedation, hastens the onset of sensory block but has no effect on the onset of motor blockade. It prolongs the duration of sensory and motor blockade. Also, not associated with any greater change in heart rate and blood pressure following spinal anaesthesia.

\section{REFERENCES:}

1. Vincent J Collins: Principles of Anaesthesiology. General and regional anaesthesia. Third addition 1993; Vol II: 1479 - 1480.

2. Kaukinen S, Pyykko. The potentiation of halothane anaesthesia by clonidine. Acta Anaesthesiol Scand 1979; 29: 107 - 11.

3. Ghignone M, Quintin L, Duke PC, Kehler CH, Calvillo O. Effects of clonidine on narcotic requirement of fentanyl anaesthesia and endotracheal intubation. Anaesthesiology 1986; 64: 36-42.

4. Tamsen A, Gordh TE. Epidural clonidine produces analgesia. Lancet 1984; 2: $231-2$.

5. Ramsay MA, Savege TM, Simpson BR. Controlled sedation with alphaxalone - alphadolone. British Med J 1974; 2 (920): 656-9. 
6. Houston J; Clonidine hydrochloride. Review of Pharmacologic and Clinical Aspects. Prog. Cardiovascular Disease 1987; 23: 337.

7. Carabine UA, Wright PM, Moore J. Preanaesthetic Medication with clonidine: A dose response study. British J of Anaesthesia 1991; 67: 79-83.

8. Bonnet F, Buisson VB, Francois Y, Catoire P, Saada M. Effects of oral and subarachnoid clonidine on spinal anaesthesia with bupivacaine. Regional anaesthesia 1990; 15: 211-214.

9. Liu S, Chiu AA, Neal JM, Carpenter RL, Bainton BG; Gerancher JC: Oral clonidine prolongs lidocaine spinal anaesthesia in human volunteers. Anaesthesiology 1995 Jun; 82 (6); 1353-9.

10. Ota K, Namiki A, Ujike Y, Takahashi I. Prolongation of tetracaine spinal anaesthesia by oral clonidine. Anesth Analg 1992; 75: 262-4.

11. Filos KS, Patroni O, Goudas LC, Bosas 0, Kassaras A, Gartaganis S: A dose response study of orally administered clonidine as premedication in the elderly: evaluating hemodynamic safety. Anesth Analg 1993; 1185-92.

12. Ezri T, Szmuk P, Shklar B, Katz J, Geva D. Oral clonidine premedication does not prolong analgesia after herniorrhaphy under subarachnoid anaesthesia. J. Clin. Anesth 1998, Sep; 10 (6): 474-81.

13. 13. Singh H, Liu J, Gaines GY, Giesecke AH, White PF. Effect of oral clonidine premedication on spinal subarachonid blockade. Anaesthesiology Sept 1993, Vol.79, No.3A.

14. Dodd JM, Breslow MJ, Derman J, Rosen BA. Preserved sympathetic response to hypotension despite perioperative $\alpha_{2}$ agonist administration. Anesth Analg 1997; 84: 1208-10.

15. Muzi M, Godd DR, Kampine JP. Clonidine reduces sympathetic activity but maintains baro reflex responses in humans. Anaesthesiology 1992; 77: 864-71.

\begin{tabular}{|c|c|c|c|c|c|c|}
\hline & GROUP & N & \multicolumn{2}{|c|}{ MEAN \pm SD } & T & P \\
\hline \multirow{2}{*}{ Age } & GROUP C & 30 & 39.3667 & 13.7376 & \multirow{2}{*}{0.579} & \multirow{2}{*}{0.565} \\
& GROUP B & 30 & 41.2667 & 11.5935 & & \\
\hline \multirow{2}{*}{ Weight } & GROUP C & 30 & 53.6333 & 7.9848 & \multirow{2}{*}{0.107} & 0.915 \\
& GROUPB & 30 & 53.4000 & 8.8458 & & \\
\hline \multicolumn{7}{|c|}{ Table 1: Demographic data } \\
\end{tabular}

Table 1: Demographic data

\begin{tabular}{|c|c|c|c|c|c|}
\hline & \multicolumn{2}{|c|}{ GROUP } & \multirow{2}{*}{ Total } \\
\hline & & & C & B & \\
\hline \multirow{4}{*}{ Gender } & \multirow{2}{*}{ M } & Count & 25 & 22 & 47 \\
\hline & & $\%$ & $83.3 \%$ & $73.3 \%$ & $78.3 \%$ \\
\hline & \multirow{2}{*}{$\mathbf{F}$} & Count & 5 & 8 & 13 \\
\hline & & $\%$ & $16.7 \%$ & $26.7 \%$ & $21.7 \%$ \\
\hline \multirow{2}{*}{ Tota } & \multirow{2}{*}{$\mathbf{N}$} & Count & 30 & 30 & 60 \\
\hline & & $\%$ & $100 \%$ & $100 \%$ & $100 \%$ \\
\hline
\end{tabular}

Table 2: Gender Distribution 


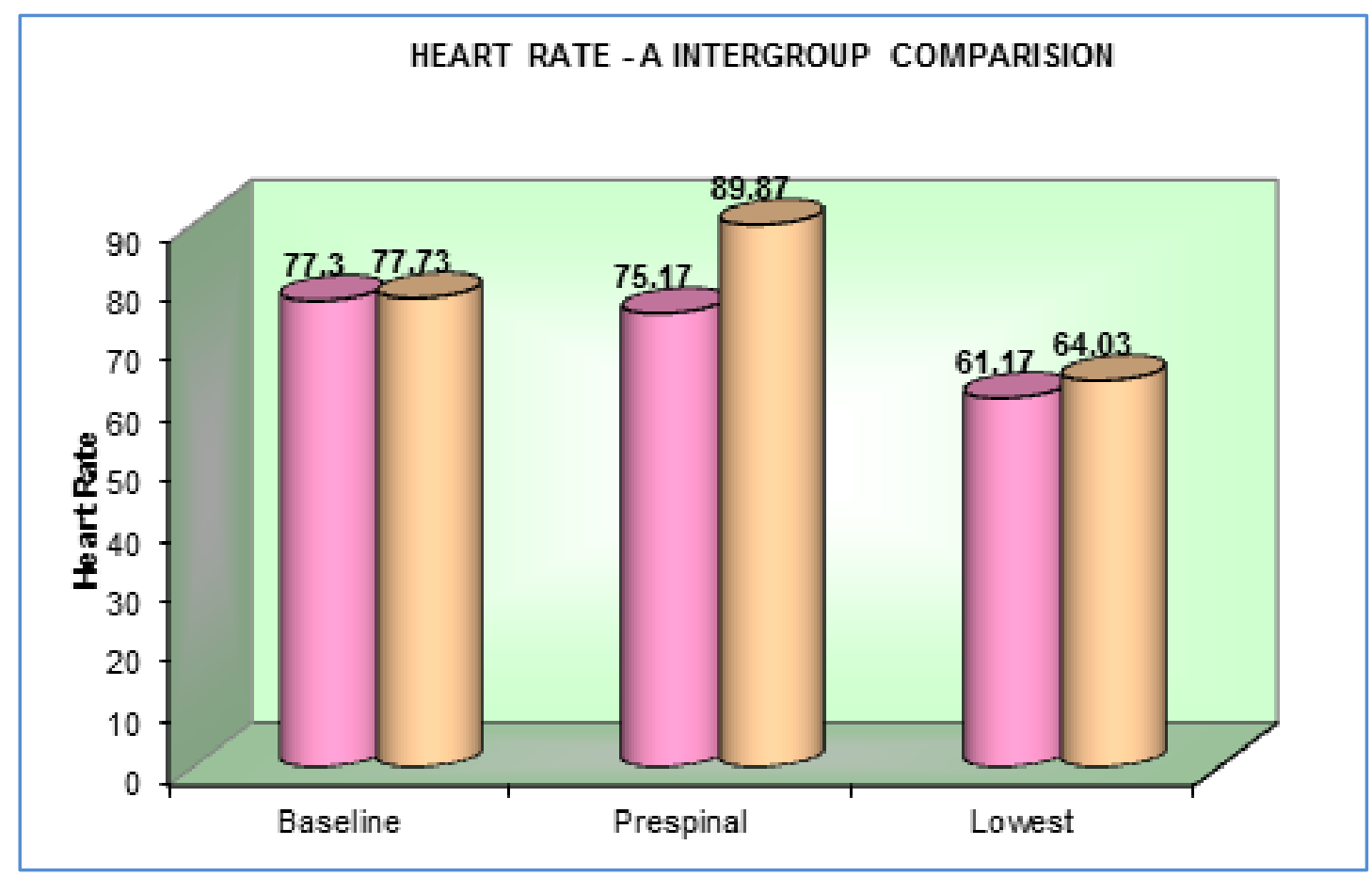

Graph 1

\begin{tabular}{|c|c|c|c|c|}
\hline GROUP & \multicolumn{2}{|c|}{ C } & \multicolumn{2}{c|}{ B } \\
\hline Scale & $\mathbf{0}^{\text {th }} \mathbf{~}$ in & $\mathbf{9 0}^{\text {th }} \mathbf{~}$ in & $\mathbf{0}^{\text {th }}$ min & $\mathbf{9 0}^{\text {th }}$ min \\
\hline \multirow{2}{*}{1} & 11 & 1 & 8 & 14 \\
& $36.66 \%$ & $3.33 \%$ & $26.66 \%$ & $46.66 \%$ \\
\hline \multirow{2}{*}{2} & 19 & 4 & 21 & 13 \\
& $63.33 \%$ & $13.33 \%$ & $70 \%$ & $43.33 \%$ \\
\hline \multirow{2}{*}{3} & 0 & 23 & 1 & 3 \\
& $0.00 \%$ & $76.66 \%$ & $3.33 \%$ & $10 \%$ \\
\hline \multirow{2}{*}{4} & 0 & 2 & 0 & 0 \\
& $0.00 \%$ & $6.66 \%$ & $0.00 \%$ & $0.00 \%$ \\
\hline \multirow{2}{*}{5} & 0 & 0 & 0 & 0 \\
& $0.00 \%$ & $0.00 \%$ & $0.00 \%$ & $0.00 \%$ \\
\hline \multirow{2}{*}{6} & 0 & 0 & 0 & 0 \\
& $0.00 \%$ & $0.00 \%$ & $0.00 \%$ & $0.00 \%$ \\
\hline \multicolumn{4}{c}{ Table 3: Distribution of sedation } \\
\hline
\end{tabular}


ORIGINAL ARTICLE

\begin{tabular}{|l|c|c|c|c|}
\hline & $\begin{array}{c}\text { G ROUP C } \\
\text { (Mean } \pm \text { SD) }\end{array}$ & $\begin{array}{c}\text { Group B } \\
\text { (Mean } \pm \text { SD) }\end{array}$ & T & P \\
\hline $\begin{array}{l}\text { Time in minute for onset of } \\
\text { highest level of sensory blockade }\end{array}$ & $11.200 \pm 3.31$ & $12.66 \pm 2.10$ & 2.045 & 0.045 \\
\hline $\begin{array}{l}\text { Time in minute for onset of } \\
\text { complete motor blockade }\end{array}$ & $5.40 \pm 2.16$ & $5.46 \pm 1.6$ & 0.107 & 0.915 \\
\hline $\begin{array}{l}\text { Time in minute for two segment } \\
\text { regression of sensory blockade }\end{array}$ & $121.10 \pm 19.71$ & $76.26 \pm 13.66$ & 10.23 & 0.00 \\
\hline $\begin{array}{l}\text { Time in minute for four segment } \\
\text { regression of sensory blockade }\end{array}$ & $172.83 \pm 20.70$ & $120.17 \pm 19.82$ & 10.06 & 0.00 \\
\hline $\begin{array}{l}\text { Time in minute of regression of } \\
\text { sensory blockade to } \mathrm{L}_{1} \text { Segment }\end{array}$ & $247.10 \pm 28.63$ & $166.47 \pm 17.99$ & 13.06 & 0.00 \\
\hline $\begin{array}{l}\text { Time for recovery of } \\
\text { motor blockade to L2 }\end{array}$ & $155.60 \pm 36.83$ & $103.63 \pm 24.99$ & 6.39 & 0.00 \\
\hline
\end{tabular}

Table 4: Comparison of onset of sensory, motor blockade and duration of analgesia

\begin{tabular}{|l|c|c|c|c|c|c|}
\hline \multirow{2}{*}{} & \multicolumn{2}{|c|}{ GROUP C } & \multicolumn{2}{c|}{ GROUP B } & \multirow{2}{*}{ T } & \multirow{2}{*}{ P } \\
\cline { 2 - 6 } & Mean & \pm SD & Mean & \pm SD & & \\
\hline Baseline & 127.7667 & 12.0106 & 131.7000 & 11.4173 & 1.300 & 0.199 \\
\hline Pre spinal & 125.8333 & 10.5245 & 130.5000 & 12.3812 & 1.573 & 0.121 \\
\hline Lowest & 106.6000 & 11.7374 & 105.8667 & 12.4339 & 0.235 & 0.081 \\
\hline $\begin{array}{l}\text { Change (baseline } \\
\text { to prespinal) }\end{array}$ & 1.9333 & 8.0598 & 1.2000 & 6.7894 & 0.381 & 0.704 \\
\hline $\begin{array}{l}\text { Change (prespinal } \\
\text { to lowest) }\end{array}$ & 19.2333 & 10.3613 & 24.6333 & 11.6722 & 1.895 & 0.063 \\
\hline
\end{tabular}

Table 5: Intergroup comparison of systolic blood pressure

\begin{tabular}{|l|c|c|c|c|c|c|}
\hline \multirow{2}{*}{} & \multicolumn{2}{|c|}{ GROUP C } & \multicolumn{2}{c|}{ GROUP B } & \multirow{2}{*}{ T } & \multirow{2}{*}{ P } \\
\cline { 2 - 5 } & Mean & \pm SD & Mean & \pm SD & & \\
\hline Baseline & 80.266 & 9.6809 & 83.5667 & 8.7639 & 1.3840 & 0.172 \\
\hline Pre spinal & 77.366 & 9.4995 & 79.9667 & 9.6932 & 0.9320 & 0 s.355 \\
\hline Lowest & 62.200 & 9.6932 & 60.5000 & 9.7264 & 0.6780 & 0.500 \\
\hline $\begin{array}{l}\text { Change (baseline } \\
\text { to prespinal) }\end{array}$ & 02.900 & 5.0538 & 03.6000 & 6.1845 & 0.4800 & 0.633 \\
\hline $\begin{array}{l}\text { Change (prespinal } \\
\text { to lowest) }\end{array}$ & 15.166 & 9.2105 & 19.4667 & 10.7663 & 1.6620 & 0.102 \\
\hline
\end{tabular}

Table 6: Intergroup comparison of diastolic blood pressure 


\section{ORIGINAL ARTICLE}

\section{AUTHORS:}

1. Shruthi Jayaram

2. Srinivas Kulkarni

3. Radhesh Hegde

\section{PARTICULARS OF CONTRIBUTORS:}

1. Assistant Professor, Department of Anaesthesiology, Hassan Institute of Medical Sciences,

2. Assistant Professor, Department of Anaesthesiology, Mysore Medical College and Research Institute

3. Professor and HOD, Department of Anaesthesiology, Father Muller Medical College.

\section{NAME ADDRESS EMAIL ID OF THE} CORRESPONDING AUTHOR:

Dr. Shruthi Jayaram,

Door No. 36, Doctor's Quarters,

H.I.M.S, Hassan-573201.

Email: shruthijayaram08@gmail.com

Date of Submission: 08/09/2014.

Date of Peer Review: 09/09/2014.

Date of Acceptance: 15/09/2014.

Date of Publishing: 20/09/2014. 